\title{
Thermodynamic and spectroscopic study on the binding of interaction anionic phthalocyanine with calf thymus DNA
}

\author{
Hamid Dezhampanah*, Termeh Darvishzad and Mehrnaz Aghazadeh \\ Laboratory of Physical Chemistry, Department of Chemistry, Faculty of Science, University of Guilan, \\ Rasht, Iran
}

\begin{abstract}
The interaction between anionic form of copper (II) $\mathrm{N}, \mathrm{N}^{\prime}, \mathrm{N}^{\prime \prime}, \mathrm{N}^{\prime \prime \prime}$-tetrasulfonated phthalocyanine $\mathrm{Cu}$ (tspc) and to calf thymus deoxyribonucleic acid (ct-DNA) is investigated by measuring UV-vis absorption and fluorescence spectroscopy in phosphate buffer. The binding constant and stoichiometry were determined by analysis of optical absorption spectra of phthalocyanine at various ct-DNA concentrations using SQUAD software. The static mode of fluorescence quenching of phthalocyanine by calf thymus deoxyribonucleic acid indicates the formation of a ground-state complex. The formation of ground-state complex is a spontaneous molecular interaction procedure in which outside groove binding through the formation of an axial bond between the base pairs of nucleotide and $\mathrm{Cu}$ in the central core of phthalocyanine.
\end{abstract}

Keywords: DNA, phthalocyanine, thermodynamic of binding, optical absorption, SQUAD

\section{Introduction}

The interaction of small molecules with DNA continues to be an extremely important area of research, in the sense of both fundamental and practical point of view, as the molecular recognition of DNA is of fundamental importance to life. DNA is an important drug target, in particular in the treatment of cancer, where many compounds that bind covalently and/or non-covalently to DNA, or damage DNA, are used. Interaction of porphyrins and metalloporphyrins with DNA has a considerable interest due to their medical applications. The ability of porphyrin to selectively cleave nucleic acid has made the porphyrins widely used as a structural probe of DNA [22]. Also, the special properties of porphyrins and metalloporphyrins, e.g., high absorbance, relatively high quantum yields of fluorescence and triplet state or paramagnetism of some metal complexes lead the use of porphyrin in medicine, as active compounds in radiological [7,31] and magnetic resonance imaging [3,20] of cancer detection. Certain porphyrins are photosensitizers and can be useful in the photodynamic therapy of cancer $[5,13,21,27]$ and act as inhibitor of HIV-I, the virus responsible for AIDS [4,26].

Three major binding modes have been proposed for the binding of porphyrin with DNA: (a) intercalation in which porphyrins intercalate into the base pairs of nucleic acids, (b) outside groove binding which involves hydrogen bonding or van der Waals interaction with the nucleic acid bases in the deep

\footnotetext{
*Corresponding author: Hamid Dezhampanah, Laboratory of Physical Chemistry, Department of Chemistry, Faculty of Science, University of Guilan, P.O. Box 1914, Rasht 0098, Iran. Tel.: +98 1313243630 5; Fax: +98 131 3233262; E-mails: h.dpanah@guilan.ac.ir; h_dpanah@yahoo.com.
} 
major groove or the shallow minor groove of the DNA helix and (c) outside binding with self-stacking involving porphyrins are stacked along the DNA helix. Intercalators have been widely used as antitumor, antineoplastic, antimalarial, antibiotic agents [15]. Like intercalators, groove binders have proven clinical utility as anti-cancer and antibacterial agents [15]. A great deal of works $[6,12,17,18,23,25,28]$ have been studied on the interactions of cationic porphyrins with DNA as the formation of porphyrin-DNA complexes, one of the most important steps in effective therapeutic treatment of tumor activity, is known to be facilitated by the electrostatic attractions between the periphery of cationic porphyrins and the anionic phosphate backbone of DNA. Actually, cationic porphyrins are considered as double functional compounds that strongly bind to DNA and photodynamically modify the target site of a DNA molecule by a mechanism similar to that of anti-cancer antibiotics such as bleomycin and daunomycin based on the DNA cleavage $[2,14,22]$.

Phthalocyanines differ from porphyrins by having nitrogen atoms link the individual pyrrol units. They have been extensively studied as DNA binders. A long triplet lifetime and a relatively high triplet quantum yield, which are useful qualities for a photosensitizer, characterize metallophthalocyanines containing diamagnetic metal ions such as $\mathrm{Al}^{+3}$ and $\mathrm{Zn}^{+2}$ [16]. Positively charged phthalocyanines possess promising photosensitizing properties for the photodynamic therapy of cancer, showing a higher photodynamic activity in vitro than the commonly used haematoporphyrin [29]. It has been observed that the uptake and the killing of cells are higher for positively charged sensitizers than for neutral or negatively charged ones [30].

On the other hand, the interaction of anionic molecules with DNA has not been as well studied [11]. In this paper we have investigated the interaction of an anionic phthalocyanine with calf thymus DNA (ct-DNA). We have used here the anionic form to examine whether this negatively charged phthalocyanine could form phthalocyanine-DNA complex which is essential for designing anti-cancer drugs in biotechnology.

In the present investigation we have studied the interaction of water-soluble phthalocyanine, copper (II) $\mathrm{N}, \mathrm{N}^{\prime}, \mathrm{N}^{\prime \prime}, \mathrm{N}^{\prime \prime \prime}$-tetrasulfonated phthalocyanine $\mathrm{Cu}$ (tspc) (Scheme 1) as an anionic metal phthalocyanine, with ct-DNA at various temperatures. The interaction process has been followed using UV-vis optical absorption, fluorescence spectroscopy. The spectral data was analyzed in order to obtain the

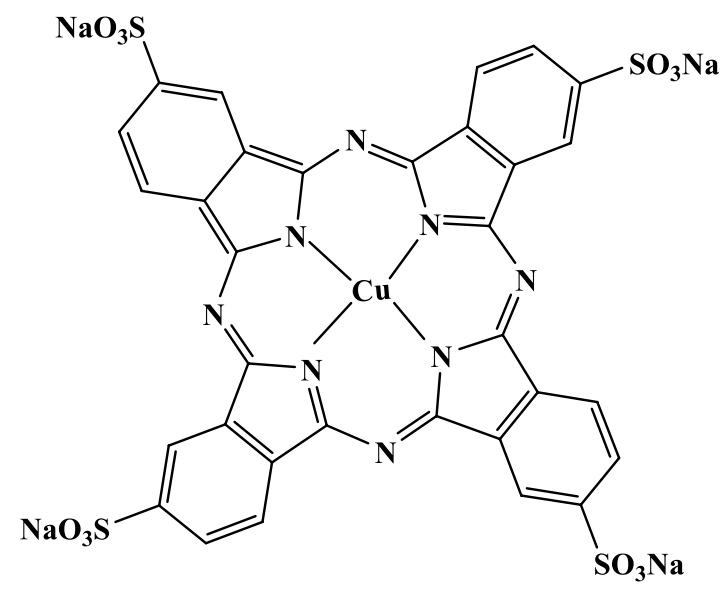

Scheme 1. Chemical structure of $\mathrm{Cu}(\mathrm{tspc})$. 
mode of binding and binding constant using SQUAD software. Running the interaction experiments at various temperatures, let us to estimate all of the thermodynamic parameters of interactions and obtain useful information regard binding mechanism.

\section{Experimental section}

Copper (II) $\mathrm{N}, \mathrm{N}^{\prime}, \mathrm{N}^{\prime \prime}, \mathrm{N}^{\prime \prime \prime}$-tetrasulfonated phthalocyanine $\mathrm{Cu}$ (tspc) was obtained from Sigma Chemical Co. and used as received. The stock solution of phthalocyanine complex $(2.72 \mathrm{mM})$ was prepared in $5 \mathrm{mM}$ phosphate buffer, $\mathrm{pH} 7.2$ and stored in the dark at $5-10^{\circ} \mathrm{C}$. Dilution of complex stock solution in the appropriate buffer was prepared immediately before use and that concentration determined.

Spectrophotometric measurements were carried out using a UV-vis double beam spectrophotometer Shimadzo model Uv-2101pc equipped with a thermostat, which controls the temperature of the cell compartment with precision of $\pm 0.1^{\circ} \mathrm{C}$.

In typical titration experiments, $2.0 \mathrm{ml}$ solutions of $\mathrm{Cu}(\mathrm{tspc})\left(6.10 \times 10^{-5} \mathrm{M}\right)$, was titrated with DNA solution $\left(9.60 \times 10^{-4} \mathrm{M}\right)$. UV-vis spectra were recorded in the range of $200-800 \mathrm{~nm}$ after each addition $(34 \mu \mathrm{l})$ of DNA solution. It has been checked that this maintenance time is enough to reach the equilibrium of the DNA-Cu (tspc) reaction. 50 wavelengths showing suitable absorbance variations upon addition of ct-DNA were selected and the equilibrium constant, $K$, was calculated by using the SQUAD program.

Calf thymus DNA was obtained from Sigma Chemical Co. and was used without further purification. To prepare the DNA stock solution, about $2 \mathrm{mg}$ of DNA was dissolved in $1 \mathrm{ml}$ of the phosphate buffer at $4^{\circ} \mathrm{C}$ for $48 \mathrm{~h}$ with occasional stirring to ensure the formation of a homogenous solution. DNA concentration in base pairs determined spectrophotometrically with the extinction coefficient of $\mathrm{DNA}=1.320 \times 10^{4} \mathrm{M}^{-1} \mathrm{~cm}^{-1}$ at $260 \mathrm{~nm}$ [24]. All other chemical reagents were analytical grade and purchased from Sigma Chemical Co., Merck and Aldrich companies. All experiments were carried out in doubly distilled water. Phthalocyanine-DNA solutions were formed with slow mixing of reagents at appropriate concentrations. Beer's law was followed during the titration.

ct-DNA do not show any fluorescence emission spectra but emission of $\mathrm{Cu}$ (tspc) complex is quenched due to its interaction with DNA. Emission spectra were recorded on a spectrofluorimeter Shimadzu model RF-5000. In a typical experiment, titration of $22 \mu \mathrm{l}$ of a phthalocyanine solution $\left(1.10 \times 10^{-3} \mathrm{M}\right)$ in $5 \mathrm{mM}$ phosphate buffer, $\mathrm{pH} 7.2$ with DNA was performed by stepwise addition of ct-DNA solution $\left(2.90 \times 10^{-4} \mathrm{M}\right)$ in the same buffer directly to the cuvette. The solutions were excited at $296 \mathrm{~nm}$ and the emitted light intensity was measured at $357 \mathrm{~nm}$, respectively. The observed fluorescence intensities were also corrected for dilution and temperature was kept constant at $25^{\circ} \mathrm{C}$ during titration experiments.

\section{Results and discussion}

\subsection{Optical absorption}

\subsubsection{Solution properties of $\mathrm{Cu}(\mathrm{tspc})$}

In order to identify the solution properties of this phthalocyanine UV-vis spectroscopy was employed. Optical absorption spectrum of $\mathrm{Cu}$ (tspc) shows two major electronic absorption bands, namely the $\mathrm{B}$ (or soret) band at approximately $340 \mathrm{~nm}$ in ultraviolet and Q-band between 600 and $700 \mathrm{~nm}$ (visible). As 
an extensively conjugated aromatic chromophore the electronic transitions have $\pi \rightarrow \pi^{*}$ character. The molar extinction coefficient of the Q-band of the $\mathrm{Cu}$ (tspc) in our experimental conditions was $3.14 \times$ $10^{4} \mathrm{~cm}^{-1} \mathrm{M}^{-1}$ at $25^{\circ} \mathrm{C}$. The Q-band absorption obeys Beer's law over an extended concentration range to $10^{-4} \mathrm{M}$ in phosphate buffer $5 \mathrm{mM}, \mathrm{pH}=7.2$ at $25^{\circ} \mathrm{C}$. After the upper limit of this concentration range, a negative deviation has been observed that corresponds to the self-association of this phthalocyanine due to the increasing concentration.

\subsubsection{Interaction of $\mathrm{Cu}(\mathrm{tspc})$ with $c t-D N A$}

The results of a titration experiment $\mathrm{Cu}$ (tspc) with ct-DNA is shown in Fig. 1. The DNA concentration varied from zero to $9.98 \times 10^{-5} \mathrm{M}$ and the concentration of phthalocyanine was $2.91 \times 10^{-5} \mathrm{M}$ for the copper (II) complex. The absorption spectrum of $\mathrm{Cu}$ (tspc) displays a Q-band at $610 \mathrm{~nm}$. A considerable hypochromicity without any red-shift in the Q-band of phthalocyanine is caused by its interaction with the DNA surface. It can be deduced that copper (II) complex to coordinate to the DNA base pairs. In other words, the copper (II) center of phthalocyanine is presumably coordinated by the carbonyl group of thymine and/or the ring nitrogen of the base pairs. Such a coordination interaction has been reported in the literature [1,19].

The absorption spectra changes of copper (II) phthalocyanine in the presence of DNA reflect the extent of phthalocyanine-DNA complexation and make possible the determination of the binding constant, $K$, using the SQUAD program.

This program has been developed to enable the evaluation of the best set of binding constants of the proposed equilibrium model by employing a nonlinear least-squares approach $[9,10]$. The input data consist of the absorbance values and the total DNA and phthalocyanine concentrations. The GaussNewton nonlinear least-squares algorithm is used for minimizing the residual sum of squares, $U$, which

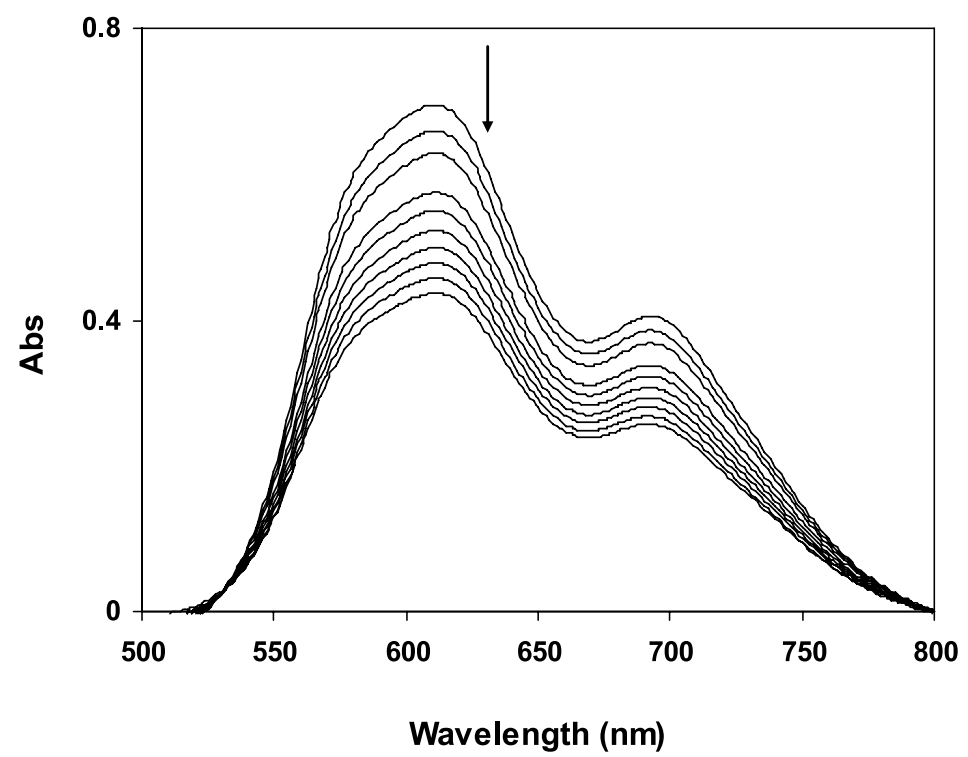

Fig. 1. UV-vis spectra of $\mathrm{Cu}(\mathrm{tspc})\left(2.91 \times 10^{-5} \mathrm{M}\right)$ in the presence of DNA at pH 7.2, [DNA]: (1) 0, (2) 31.50 , (3) 58.8 , (4) 69.7, (5) 80.50 , (6) 90.80 , (7) 93.80 , (8) 95.90 , (9) 97.50 , (10) $99.80 \mu \mathrm{M}$. The arrow indicates the fluorescence intensity change with increasing [ct-DNA]. 
is calculated from Eq. (1):

$$
U_{\mathrm{obs}}=\sum_{i=1}^{I} \sum_{k=1}^{N W}\left(A_{i, k}^{\mathrm{cal}}-A_{i, k}^{\mathrm{obs}}\right)^{2},
$$

where $A_{i, k}^{\text {obs }}$ is the absorbance value of the $i$ th solution at $k$ th wavelength, give a total of $I$ solutions and a grand total of $N W$ wavelengths (in our experiments $I=15$ and $N W=50$ ). The output data are the logarithm of the macroscopic binding constant $\left(K_{i j}\right)$ for formation of $D_{i} P_{j}$, where $D$ is DNA and $P$ is phthalocyanine corresponds to the following equilibrium:

$$
i D+j P \leftrightarrow D_{i} P_{j}
$$

The values of $U$ and the percent error represent the uncertainty in $\log K_{i j}$ calculated by the program. The absorption data were analyzed by assuming $1: 1$ or 2:1 and/or simultaneous 1:1 and 2:1 molar ratios of phthalocyanine to DNA. Fitting of the experimental data (15 points), to the proposed stoichiometric models was evaluated by the sum of squares of the calculated points by the model. The results show that the best fitting corresponds to the 1:1 complex model at studied temperatures with the residual sum of squares, $U$, ranging between $10^{-4}$ and $10^{-3}$.

\subsubsection{Thermodynamics of DNA-phthalocyanine binding process}

The binding studies were carried out at $20,25,30,35$ and $40^{\circ} \mathrm{C}$. At these temperatures, DNA does not undergo any structural degradation. The binding constant at any specified temperature was determined by the concentration dependence of UV-vis absorption data, using SQUAD program. The energetics of DNA-phthalocyanine equilibrium can be conveniently characterized by three thermodynamic parameters, standard Gibbs free energy, $\Delta G^{o}$, the standard molar enthalpy, $\Delta H^{o}$ and the standard molar entropy, $\Delta S^{o} . \Delta G^{o}$ can be calculated from the equilibrium constant, $K$, of the reaction using the familiar relationship, $\Delta G^{o}=-R T \ln K$, in which $R$ and $T$ refer to the gas constant and the absolute temperature, respectively.

The van't Hoff equation gives a linear plot of $\ln K$ versus $1 / T$, if the heat capacity change for the reaction is essentially zero:

$$
\frac{\mathrm{d} \ln K}{\mathrm{~d}(1 / T)}=-\frac{\Delta H^{o}}{R}
$$

The $\Delta H^{o}$ can be calculated from the slope of the straight line, $-\Delta H^{o} / R$ and the standard entropy by the following equation (Eq. (4)):

$$
\Delta S^{o}=\frac{\Delta H^{o}-\Delta G^{o}}{T} .
$$

The van't Hoff plots for binding of this phthalocyanine to DNA in the phosphate buffer is shown in Fig. 2. All of the thermodynamic parameters with their uncertainties for interaction with $\mathrm{Cu}(\mathrm{tspc})$ was calculated, and reported in Table 1.

The negative signs of $\Delta G^{o}$ indicate the spontaneity of the binding processes of ct-DNA with $\mathrm{Cu}$ (tspc) at the five temperatures. It is also observed from the Table 1 that binding of $\mathrm{Cu}$ (tspc) to ct-DNA is an exothermic process. From the Table 1 it is clear that the favorable free energy changes of the binding 


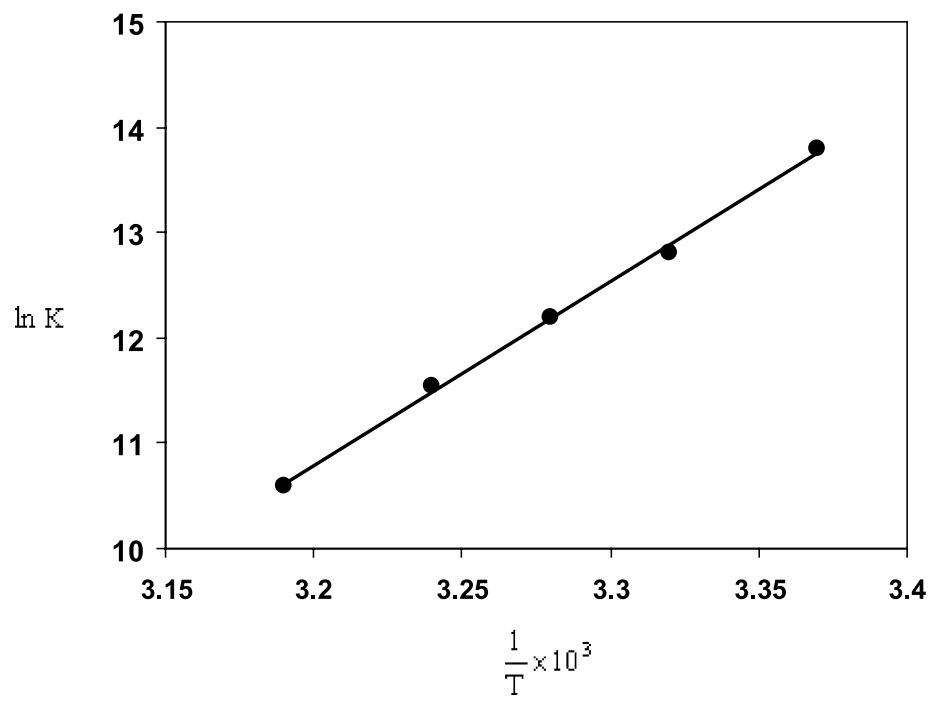

Fig. 2. The van't Hoff plot of DNA binding of $\mathrm{Cu}(\mathrm{tspc})$.

Table 1

Calculated thermodynamic parameters for binding of $\mathrm{Cu}$ (tspc) to ct-DNA in $5 \mathrm{mM}$ phosphate buffer $\mathrm{pH} 7.2$, at $25^{\circ} \mathrm{C}$

\begin{tabular}{lcccc}
\hline$T(\mathrm{~K})$ & $(K \pm \Delta K) \times 10^{5}\left(M^{-1}\right)$ & $\Delta G^{o}\left(\mathrm{~kJ} \cdot \mathrm{mol}^{-1}\right)$ & $\Delta H^{o}\left(\mathrm{~kJ} \cdot \mathrm{mol}^{-1}\right)$ & $\Delta S^{o}\left(\mathrm{~J} \cdot \mathrm{mol}^{-1} \mathrm{~K}^{-1}\right)$ \\
\hline 293.15 & $9.85 \pm 1.02$ & $-33.63 \pm 0.06$ & $-144.85 \pm 0.12$ & $-379.39 \pm 0.21$ \\
298.15 & $3.62 \pm 1.03$ & $-31.72 \pm 0.6$ & $-144.85 \pm 0.12$ & $-379.43 \pm 0.25$ \\
303.15 & $1.98 \pm 1.03$ & $-30.73 \pm 0.05$ & $-144.85 \pm 0.12$ & $-376.44 \pm 0.28$ \\
308.15 & $1.04 \pm 1.02$ & $-29.59 \pm 0.06$ & $-144.85 \pm 0.12$ & $-374.03 \pm 0.25$ \\
313.15 & $0.40 \pm 1.02$ & $-27.58 \pm 0.07$ & $-144.85 \pm 0.12$ & $-374.88 \pm 0.25$ \\
\hline
\end{tabular}

process arise from the large negative enthalpy changes. Thus this binding process is enthalpically driven rather than the entropically driven. This can be related to the special role of copper (II) in formation of complex with DNA. Probably, the axial ligation of copper (II) with carbonyl group of thymine and/or the ring nitrogen of the base pairs group increases its affinity to DNA.

\subsection{Fluorescence spectroscopic studies}

For this study, the fluorescence behavior of $\mathrm{Cu}$ (tspc) has been monitored. Figure 3 shows the emission spectrum of $\mathrm{Cu}(\mathrm{tspc})$ in presence of increasing concentrations of ct-DNA. The emission maximum intensity of $\mathrm{Cu}$ (tspc) gradually decreased. It can be seen that the fluorescence of $\mathrm{Cu}$ (tspc) was efficiently quenched at the maximum emission wavelength $375 \mathrm{~nm}$ upon addition of ct-DNA, indicating that the $\mathrm{Cu}(\mathrm{tspc})$ binding to DNA changes the excited state electronic structure of $\mathrm{Cu}$ (tspc) fluorophore.

A quantitative estimation of the quenching in terms of the fluorescence-quenching constant was analyzed using the Stern-Volmer equation (5) [8]:

$$
\frac{F_{o}}{F}=1+K_{\mathrm{Sv}}[Q]
$$

where $F_{o}$ and $F$ are the fluorescence intensities in absence and presence of the quencher (ct-DNA), respectively, $K_{\mathrm{SV}}$ is the Stern-Volmer quenching constant and $[Q]$ the quencher concentration. The 


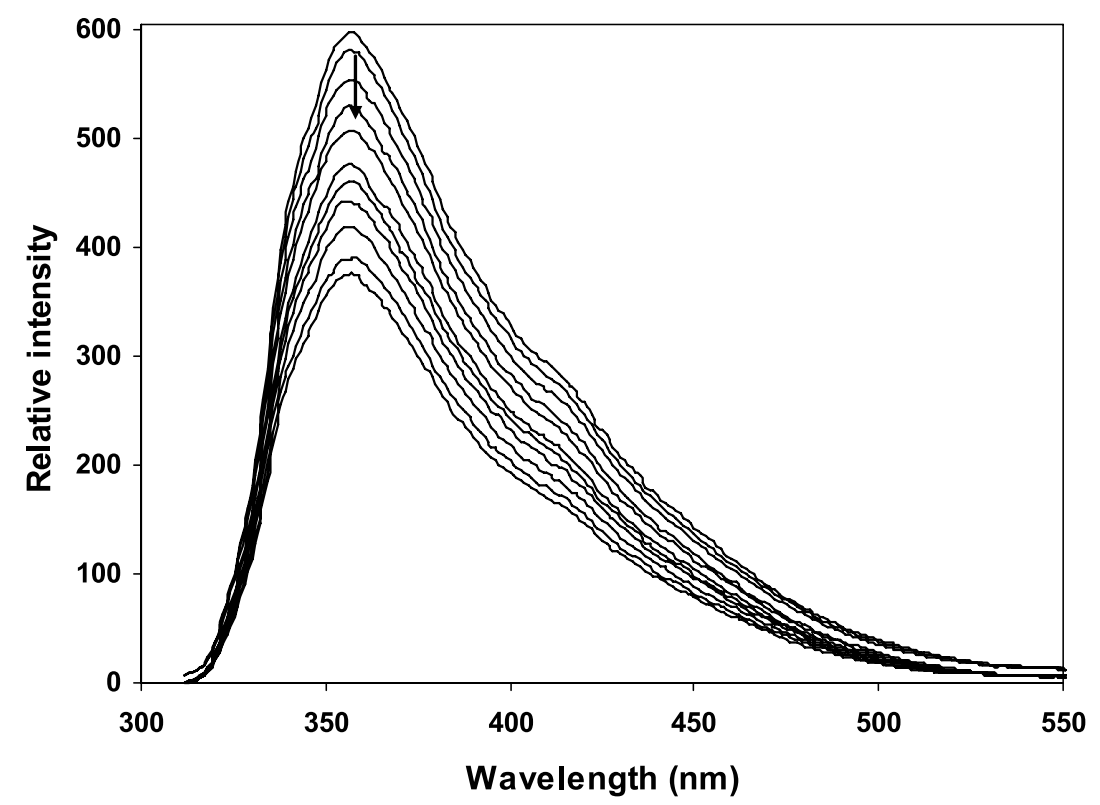

Fig. 3. Emission spectra of $\mathrm{Cu}(\mathrm{tspc})(29.15 \mu \mathrm{M})$ in absence (top) and presence of ct-DNA $(10.51-80.71 \mu \mathrm{M})$ in phosphate buffer $\mathrm{pH}$ 7.20. The arrow indicates the fluorescence intensity change with increasing [ct-DNA].

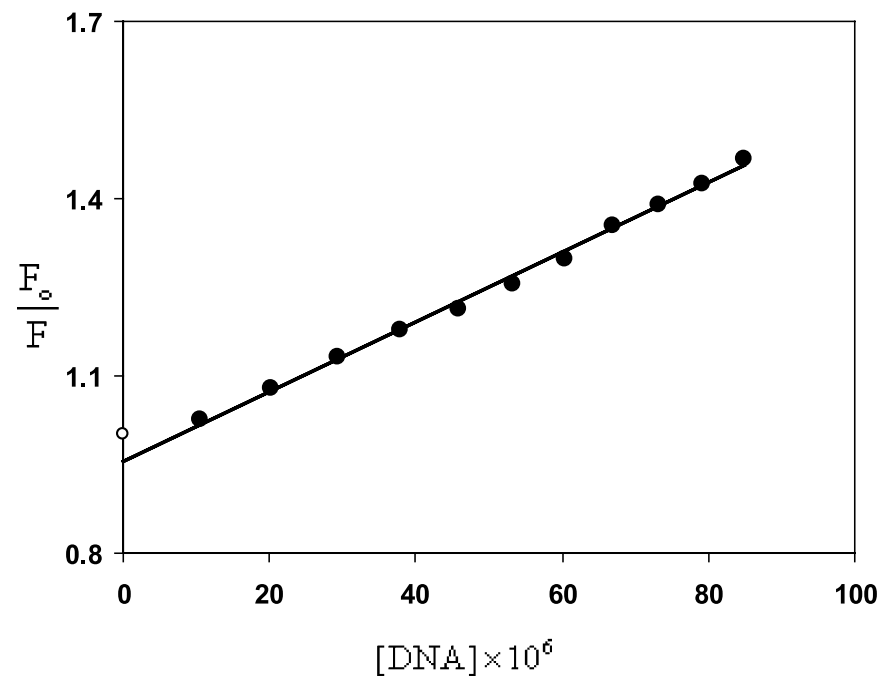

Fig. 4. Stern-Volmer plot: $\mathrm{Cu}$ (tspc) $(29.15 \mu \mathrm{M}) ;$ [ct-DNA] $=(10.51-80.71 \mu \mathrm{M}) ; \lambda_{\mathrm{ex}}=357 \mathrm{~nm}$.

quenching constant may be obtained from the slope of the Stern-Volmer plot $\left(\frac{F_{O}}{F}\right.$ versus $\left.[Q]\right)$. The representative plot of $\frac{F_{O}}{F}$ versus $[Q]$ (Fig. 4) of the present system shows a slight downward curvature at higher concentrations with addition of ct-DNA. The quenching constant $\left(K_{\mathrm{SV}}\right)$, calculated in the linear range $(10.51$ to $80.71 \mu \mathrm{M})$ was found to be $5.9 \times 10^{3} \mathrm{M}^{-1}\left(R^{2}=0.99\right)$. 


\section{Conclusions}

UV-vis spectroscopy enabled us to determine the phthalocyanine-DNA binding constants and thermodynamic parameters. It was deduced that the binding interactions are exothermic and enthalpy driven. The existence of the high hypochromicity without any shift in the visible part of the $\mathrm{Cu}$ (tspc) spectra suggest an outside groove binding mode. It is assumed that the steric constraints presented by the water axial ligand at the metal center of the copper (II) phthalocyanines serve to prevent intercalation into DNA.

Quenching studies of the phthalocyanine by DNA complex gave us the Stern-Volmer constant.

In summary, we believe that this complex has a good affinity for DNA binding. This type of investigation can provide important insight in designing anti-cancer drugs in biotechnology.

\section{Acknowledgement}

The financial support of Research Council of Guilan University is gratefully acknowledged.

\section{References}

[1] M. Asadi, E. Safaei, B. Ranjbar and L. Hasanib, New J. Chem. 28 (2004), 1227-1234.

[2] R.M. Burger, Cleavage of nucleic acids by bleomycin, Chem. Rev. 98 (1998), 1153.

[3] C. Chen, J.S. Cohen, C.E. Myers and M. Sohn, FEBS Lett. 168 (1984), 70.

[4] L. Ding, L. Balzarini, D. Schols, B. Meunier and E. De Clercq, Biochem. Pharmacol. 44 (1992), 1675.

[5] R.J. Fiel, N. Datta-Gupta, E.H. Mark and J.C. Howard, Cancer Res. 41 (1981), 3543.

[6] T.A. Gray, K.T. Yue and L.G. Marzilli, J. Inorg. Biochem. 41 (1991), 205-219.

[7] P. Hambright, R. Fawwaz, P. Valk, J. McRae and A.J. Bearden, Bioinorg. Chem. 5 (1975), 87-92.

[8] J.R. Lakowicz, Principles of Fluorescence Spectroscopy, 3rd edn, Springer, New York, 2006.

[9] D.J. Leggett, S.L. Kelly, L.R. Shiue, Y.T. Wu, D. Chang and K.M. Kadish, Talenta 30 (1983), 579.

[10] D.J. Leggett and W.A.E. McBryde, Anal. Chem. 47 (1975), 1065.

[11] Y. Li, R. Geyer and D. Sen, Biochemistry 35 (1996), 6911-6922.

[12] N.E. Mukundan, G. Petho, D.W. Dixon and L.G. Marzilli, Inorg. Chem. 34 (1995), 3677.

[13] D.A. Musser, N. Datta-Gupta and R.J. Fiel, Biochem. Biophys. Res. Commun. 97 (1980), 918.

[14] S. Niedle and M.R. Sanderson, in: Molecular Aspects of Anti Cancer Drug Action, S. Neidle and M.J. Waring, eds, Verlag Chemie GmBH, Weinheim, 1983, pp. 35-56.

[15] R. Palchaudhuri and P.J. Hergenrother, Curr. Opin. Biotechnol. 18 (2007), 497.

[16] B. Paquette and J.E. van Lier, in: Phthalocyanines and Related Compounds: Basic Principles and Clinical Applications, B.W. Henderson and T.J. Dougherty, eds, Marcel Decker, Inc., New York, Basel, Hong Kong, 1992, p. 145.

[17] R.F. Pasternack, R.A. Brigandi, M.J. Abrams, A.P. Williams and E.J. Gibbs, Inorg. Chem. 29 (1990), 4483-4486.

[18] R.F. Pasternack, C. Bustamante, P.J. Collings, A. Giannetto and E.J. Gibbs, J. Am. Chem. Soc. 115 (1993), 5393.

[19] R.F. Pasternack, K.F. Schaefer and P. Hambright, Inorg. Chim. Acta 33 (1994), 2062.

[20] N.J. Patronas, M. Cohen, R.H. Knop, A.J. Dwyer, D. Colcher, J. Lundy, F. Mornex, P. Hambright, M. Sohn and C.E. Myers, Cancer Treat. Rep. 70 (1986), 391.

[21] D. Praseuth, A. Gaudemer, J.-B. Verlhac, I. Kraljic, I. Sissoeff and E. Guille, Photochem. Photobiol. 44 (1986), 717.

[22] G. Pratviel, J. Bernadou and B. Meunier, Selective DNA cleavage by metalloporphyrin derivatives, in: Metal Ions in Biological Systems, H. Sigel, ed., Vol. 33, Marcel Dekker, New York, 1996, p. 399.

[23] M.A. Sari, J.P. Battioni, D. Dupre, D. Mansuy and J.B. Le Pecq, Biochemistry 29 (1990), 4205.

[24] D.E.V. Schmechel and D.M. Crothers, Biopolymers 10 (1971), 465.

[25] U. Sehlstedt, S.K. Kim, P. Carter, J. Goodisman, J.F. Vollano, B. Noren and J.C. Dabrowiak, Biochemistry 33 (1994), 417.

[26] J.L. Sessler, M.J. Cyr, V. Lynch, E. McGhee and J.A. Ibers, J. Am. Chem. Soc. 112 (1990), 2810.

[27] A. Villanueva, M.J. Hazen and J.C. Stockert, Experientia 42 (1986), 1269.

[28] R.K. Wall, A.H. Shelton, L.C. Bonaccorsi, S.A. Bejune, D. Dubé and D.R. McMillin, J. Am. Chem. Soc. 123 (2001), 11480 . 
[29] D. Wohrle, N. Iskandar, G. Graschev, H. Sinn, E.A. Friedrich, W. Maier-Borst, J. Stern and P. Schlag, Photochem. Photobiol. 51 (1990), 351.

[30] S.R. Wood, J.A. Hotroyd and S.B. Brown, Photochem. Photobiol. 65 (1997), 397.

[31] G.D. Zanelli and A.C. Kaelin, Brit. J. Radiol. 54 (1981), 403. 


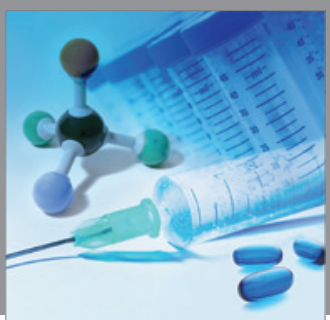

International Journal of

Medicinal Chemistry

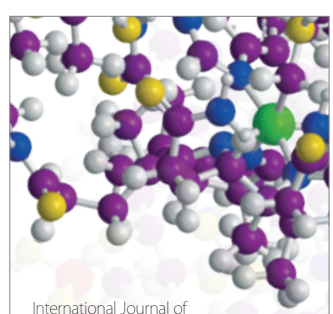

Carbohydrate Chemistry

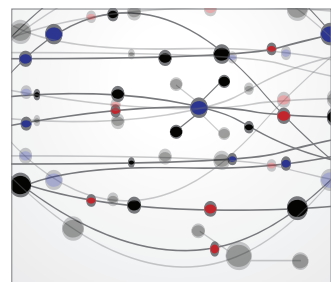

The Scientific World Journal
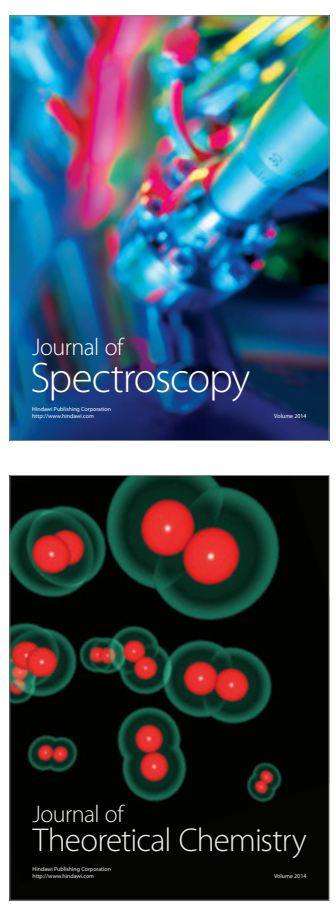
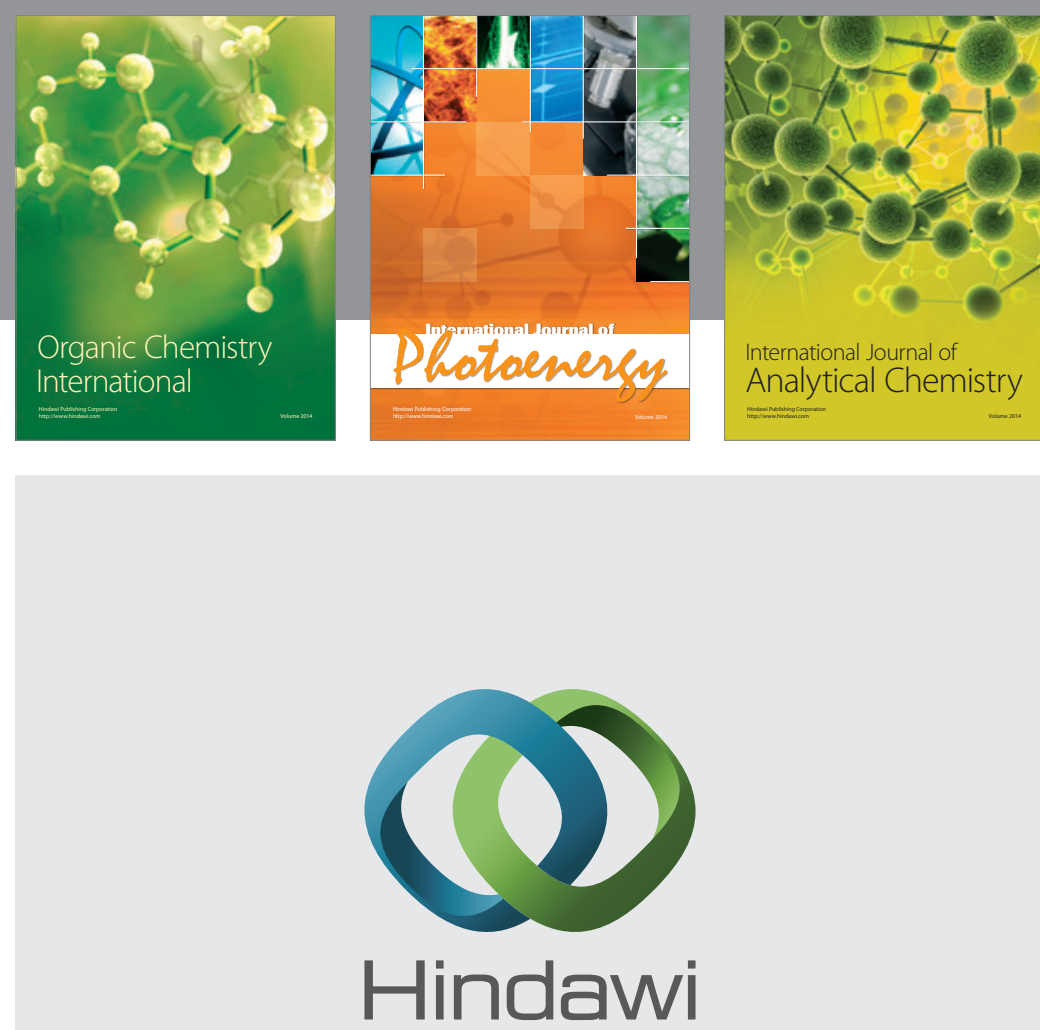

Submit your manuscripts at

http://www.hindawi.com
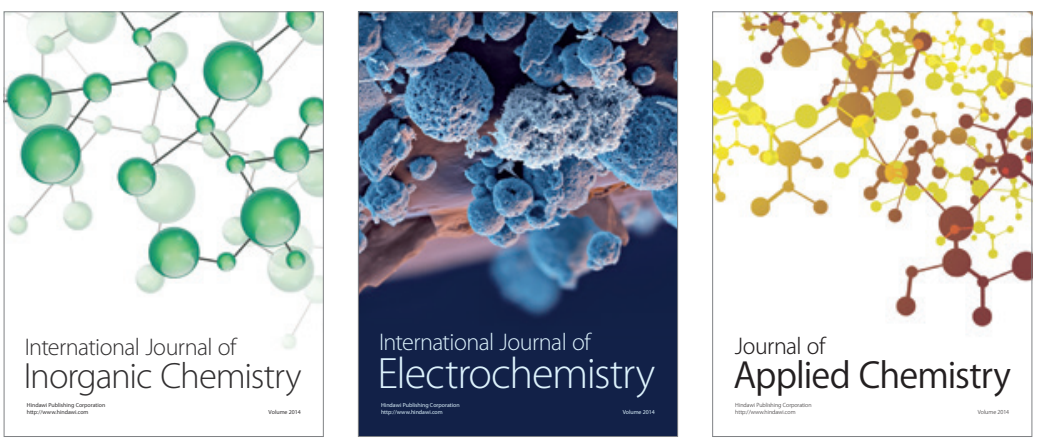

Journal of

Applied Chemistry
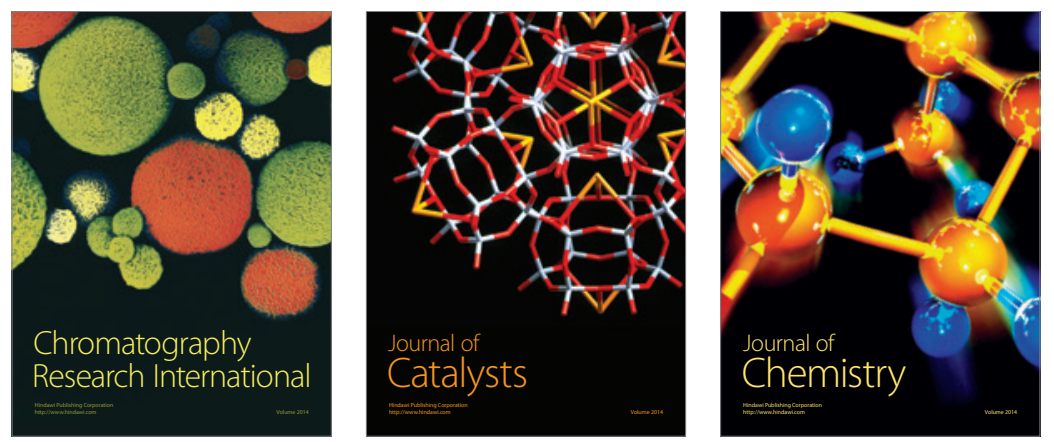
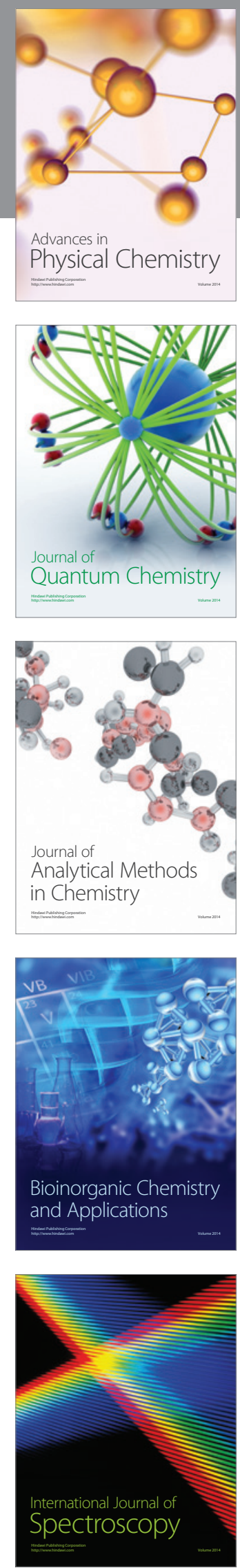